\title{
Effect of Moxifloxacin Administration on Pharmacokinetics of Tolfenamic Acid in Rats
}

\author{
Satish D. Patel ${ }^{2}$, Kamlesh A. Sadariya ${ }^{2}$, Anil K. Gothi ${ }^{2}$ Urvesh D. Patel ${ }^{1}$, Pradhuman A. \\ Gohil $^{1}$, Mukul R. Jain ${ }^{1}$, Shailesh K. Bhavsar ${ }^{3 *}$ and Aswin M. Thaker ${ }^{2}$ \\ ${ }^{1}$ Zydus Research Centre; Cadila healthcare limited; Gujarat - Ahmedabad. ${ }^{2}$ Department of Pharmacology and \\ Toxicology; Veterinary College; Anand Agricultural University; Anand - India. ${ }^{3}$ Department of Pharmacology and \\ Toxicology; Veterinary College; NavsariAgricultural University; Navsari - India
}

\begin{abstract}
Pharmacokinetics of tolfenamic acid as a single drug (4 $\mathrm{mg} / \mathrm{kg}$, intramuscularly) and its co-administration with moxifloxacin $(5 \mathrm{mg} / \mathrm{kg}$, intramuscularly) in wistar rats were studied. The plasma drug concentration of tolfenamic acid was assayed by LC-MS/MS. Following intramuscular administration of tolfenamic acid as single drug and in combination with moxifloxacin in male rats, the mean values of observed peak plasma drug concentration $\left(C_{\text {max }}\right)$, area under plasma drug concentration-time curve $\left(A U C_{(0-\infty)}\right)$, volume of distribution $(V z)$, half-life $\left(t_{1 / 2}\right)$ and clearance (Cl) were $4111.44 \pm 493.15$ and $3837.69 \pm 351.83 \mathrm{ng} / \mathrm{ml}, 20280.77 \pm 3501.67$ and $15229.18 \pm 678.80 \mathrm{ng} . \mathrm{h} / \mathrm{ml}$, $822.17 \pm 115.38$ and $1249.64 \pm 139.52 \mathrm{ml}, 2.59 \pm 0.16$ and $3.27 \pm 0.32 \mathrm{hr}$, and $218.39 \pm 25.47$ and $265.18 \pm 11.36$ $\mathrm{ml} / \mathrm{hr}$, respectively. The peak plasma drug concentration $\left(C_{\text {max }}\right)$ was significantly higher in female rats compared to male rats. The volume of distribution $(V z)$ of the drug was significantly higher $(P<0.05)$ in moxifloxacin-treated male rats compared to female rats. Concomitant administration of moxifloxacin may alter the disposition of tolfenamic acid in male rats.
\end{abstract}

Key words: Pharmacokinetics, Tolfenamic acid, anti inflammatory drug, rats, interaction, Moxifloxacin

\section{INTRODUCTION}

Tolfenamic acid (TA) is a non-steroidal antiinflammatory drug (NSAID) of the fenamate group, which has been commonly used to reduce the pain and inflammation in different arthritic and postoperative conditions (Lombardino and Wiseman 1982, Hawkey, 1999). It inhibits the biosynthesis of prostaglandins and also has an inhibitory action on prostaglandin receptors. Moreover, it also produces inhibition of cyclooxygenase and lipoxygenase (Linden et al. 1976, Proudman and McMillan, 1991; Kankaanranta et al. 1991). Tolfenamic acid has also been found a potent inhibitor of thromboxane $\mathrm{B}_{2}$ synthesis (McKellar et al. 1991). It possesses antiinflammatory, analgesic, antipyretic and antiendotoxaemic properties (Rejholec et al. 1979). The pharmacokinetics of tolfenamic acid has been evaluated in the dogs (McKellar et al. 1991), men (Pentikainen et al. 1981, 1984) and horses (Jaussand et al. 1991). TA was rapidly eliminated mainly by transformation to several metabolites. About $10 \%$ of dose of TA has been found to excrete in urine in unchanged form and its

\footnotetext{
*Author for correspondence: skbhavsar@aau.in
} 
glucoronide and sulfate conjugate (Pentikainen, et al. 1984; Pedersen, 1994).

Pharmacokinetic interaction is result of alterations of drug absorption, distribution, metabolism and elimination in combination therapy. Newer flouroquinolone antimicrobials have been widely used in the clinical field because of their high clinical efficacy and safety, and are often administered concomitantly with NSAIDs to treat a broad range of infections. Moxifloxacin is a newer fourth-generation, 8-methoxy quinolone having antimicrobial activity against a wide range of grampositive and gram-negative microorganisms, anaerobic bacteria and atypical respiratory pathogens (Dalhoff et al. 1996; Miravitlles, 2007). The aim of this study was to evaluate the effect of moxifloxacin administration on pharmacokinetics of tolfenamic acid in rats.

\section{MATERIAL AND METHODS}

\section{Animals}

The study was conducted on 24 adult healthy male and female wistar rats. The rats were housed in individually ventilated polysulphone cages (IVC) under standard laboratory conditions. The full system was kept in environmentally controlled room at $22 \pm 3{ }^{\circ} \mathrm{C}$ and $30-70 \%$ humidity. Light/dark cycles of $12 / 12 \mathrm{~h}$ were provided throughout the study period. Rats of 6-8 weeks age were selected after physical examination (skin, fur, eyes, mucous membrane, occurrence of secretions, lacrimation, piloerection, pupil size, unusual respiratory pattern) and behavioral examination (gait, posture and response to handling). Nulliparous and non -pregnant female rats were used in the study. The live body weight range was within $\pm 20 \%$ of the mean body weight for each sex at the time of randomization. Food and water were provided ad libitum. The experimental protocol for general procedures and use of animals was approved by the Institutional Animal Ethics Committee (IAEC). The rats were kept under constant observation for seven days before the commencement of experiment. At the time of drug administration, the age of animals was 7-9 weeks. All necessary managemental procedures were adopted to keep the rats free from stress.

\section{Drugs and Chemicals}

Tolfenamic acid, moxifloxacin and atorvastatin pure base powder were obtained from the Zydus Research Centre, Ahmedabad, India. Acetonitrile of HPLC grade was purchased from Merck India Ltd., Mumbai. Methanol was procured from SD Fine Chemical Ltd., Mumbai. Dimethyl sulphoxide (DMSO), formic acid and Twin-80 were procured from Qualigens Fine Chemicals, Mumbai. Labrasol was purchased from Gattefosse, France.

\section{Experimental Design and Drug administration}

All the animals of either sex were divided into two groups of six male and six female and were treated with tolfenamic acid alone $(4 \mathrm{mg} / \mathrm{kg}$, intramuscular) and tolfenamic acid along with moxifloxacin (5 $\mathrm{mg} / \mathrm{kg}$, intramuscular), respectively. Tolfenamic acid was formulated in $30 \%$ labrasol solution in phosphate buffer saline ( $\mathrm{pH}$ 7.2) (vehicle-I), where as the moxifloxacin was formulated for dose administration in 5\% Twin-80, 5\% DMSO (dimethyl sulphoxide) in Milli-Q water (w/v) (vehicle-II). Doses were calculated according to body weight of the animals and administrated as per concentration strength of formulation. The drugs were administered by intramuscular route using sterile $1 \mathrm{ml}$ syringe and needle $(26 \mathrm{G}, 0.45 \mathrm{~mm} \times 13 \mathrm{~mm})$ in deep gluteal muscle.

Blood samples $(0.25 \mathrm{ml})$ were collected from retro-orbital plexus under anesthesia in heparinized centrifuge tube $(0.5 \mathrm{ml}$ capacity) at 0 minute (before drug administration), 10, 20, 40 minutes, 1, 2, 4, 6, 8, 12, 18, 24, 30 and $48 \mathrm{~h}$ after intramuscular administration of the drugs. The plasma was separated by centrifugation at 6000 rpm for six minutes at ambient temperature and stored in labeled cryovials at $-70{ }^{\circ} \mathrm{C}$ in deep freezer until assay.

\section{Tolfenamic assay}

The plasma samples $(100 \mu \mathrm{L})$ were transferred in 2 ml micro-centrifuge tube to which $10 \mu \mathrm{L}$ of working solution $(100 \mu \mathrm{g} / \mathrm{ml})$ of internal standard (Atorvastatin) was added. The contents were mixed by vortexing for $30 \mathrm{sec}$. Each sample was added with $300 \mu \mathrm{L}$ of acetonitrile for plasma protein precipitation and vortexed for 1 minute. Samples were centrifuged at $10,000 \mathrm{rpm}$ for $5 \mathrm{~min}$. The supernatant was transferred in HPLC vials and $5 \mu \mathrm{L}$ was injected using auto sampler (Agilent 1100 Autosampler, Germany) in LC-MS/MS system (API 3000 LC-MS/MS system, PE Sciex, USA). The 
temperature of auto sampler was $10^{\circ} \mathrm{C}$. The methodology was validated by spiking the rat plasma samples with known amounts of TA. The plasma drug concentration of TA was determined using the conditions described below.

Inertsil- $\mathrm{C}_{18}$, $(50 \mathrm{~mm} \times 4.6 \mathrm{~mm}), 5 \mu \mathrm{m}$ column was used for the separation of compounds at ambient temperature $\left(25 \pm 5^{\circ} \mathrm{C}\right)$ using column oven (Agilent 1100 , Germany). Tolfenamic acid eluted at $2.2 \mathrm{~min}$ and atorvastatin at $1.8 \mathrm{~min}$, with a total run time of $5 \mathrm{~min}$. Ions were generated using electrospray ionization and detected in the positive-ion mode.

The mobile phase consisted of $0.3 \%$ formic acid in water (Solution - A), acetonitrile (Solution- B) and methanol (Solution- C). Above solutions were used to make the mobile phase using gradient system with different ratio of solution $\mathrm{A}, \mathrm{B}$ and $\mathrm{C}$ programmed at time 0.01 (80:20:0), 1 (20:80:0), 1.5 (10:90:0), 2 (10:0:90), 2.5 (10:0:90), 3 (80:20:0) and 5 minutes (80:20:0). The mobile phase was pumped at the flow rate of $1.5 \mathrm{ml} / \mathrm{min}$ (Agilent 1100 HPLC Pump, Germany). Multiple reactions monitoring was performed using the precursor-product ion combination for tolfenamic acid (m/z 262.30) and atrovastatin $(\mathrm{m} / \mathrm{z} 559.30)$. High purity nitrogen was used as the nebulising $(10 \mathrm{~L} / \mathrm{h})$.

Accurately weighed $10.0 \mathrm{mg}$ of tolfenamic acid pure API grade powder was dissolved in diluent (acetonitrile: methanol: water in the ratio of 40:40:20) to make the concentration of $1,000 \mu \mathrm{g} / \mathrm{ml}$ (Stock solution A). Similarly, $1.0 \mathrm{mg}$ of Atorvastatin was dissolved in the diluents to make the concentration of $100 \mu \mathrm{g} / \mathrm{ml}$ (Stock solution B). Working solutions for calibration standards and quality control (QC) samples of tolfenamic acid were prepared from the stock solution A in the range of 250 to $50,000 \mathrm{ng} / \mathrm{ml}$. Working solution of internal standard was prepared by diluting $0.2 \mathrm{ml}$ of stock solution B up to $10.0 \mathrm{ml}$ with diluent in volumetric flask to get final concentration of 2.0 $\mu \mathrm{g} / \mathrm{ml}$.

Calibration samples consisted of eight different concentrations of tolfenamic over the range of 250 to $50,000 \mathrm{ng} / \mathrm{ml}$ in the diluents and plasma. The low, medium and high quality control samples $(750,4,000,40,000 \mathrm{ng} / \mathrm{ml})$ were prepared independently in diluent and rat plasma. All QC samples in the plasma were treated similar to the method described above. The mean recovery of tolfenamic acid from the plasma was $\geq 70.12 \%$ at $25 \mathrm{ng} / \mathrm{ml}$ (LLOQ). The sensitivity of tolfenamic acid assay was $25 \mathrm{ng} / \mathrm{ml}$. The assay was sensitive, reproducible and linearity was observed from 25 to $5000 \mathrm{ng} / \mathrm{ml}$ with mean correlation coefficient $\left(\mathrm{R}^{2}\right)$ of 0.9985. Intra-day and inter-day precision $( \pm 15 \%)$ and accuracy $( \pm 10 \%)$ were within standard limits. Validation parameters indicated that the method was reliable, reproducible and accurate.

\section{Pharmacokinetic and statistical analysis}

Various pharmacokinetic parameters such as absorption, distribution, and elimination half-life, apparent volume of distribution, total body clearance were determined using WinNonlin software (version 5.2, Pharsight Corporation, USA) by non-compartmental analysis. The data obtained for pharmacokinetic parameters were presented as Mean \pm SEM and analyzed statistically using unpaired two tail ' $t$ ' test for both types of factors 1) sex : male versus female; 2) treatment: tolfenamic acid only versus tolfenamic acid plus moxifloxacin. Where $\mathrm{p} \leq 0.05$ was considered as statistically significant and $p \leq 0.01$ was considered as statistically highly significant. The graphs and figures were prepared using software Graph Pad Prism (Version 4.00).

\section{RESULTS AND DISCUSSION}

Fluoroquinolones are increasingly employed in medicine to eradicate the susceptible bacterial infection. Co-administration of several drugs often may result in unpredictable therapeutic outcome. The use of non-steroidal anti-inflammatory drugs (NSAIDs) are frequently recommended with antibacterials for the treatment of various bacterial infections accompanied by fever and other inflammatory conditions in the men and animals. It is widely recognised that co-administration of two drugs may affect the absorption, distribution, biotransformation and/or excretion of both agents (Benet and Sheiner 1985). Hence, the present study was planned to evaluate the impact of moxifloxacin administration on pharmacokinetics of tolfenamic acid in wistar rats.

Following the intramuscular administration of tolfenamic acid as a single drug and along with moxifloxacin in the male rats, the mean observed peak plasma drug concentration were $4111.44 \pm$ 493.15 and $3837.69 \pm 351.83 \mathrm{ng} / \mathrm{ml}$, respectively at $1 \mathrm{~h}\left(\mathrm{~T}_{\max }\right)$. In the female rats, respective mean values were $7114.74 \pm 1409.96$ and $7436.37 \pm 518.67 \mathrm{ng} / \mathrm{ml}$, respectively at $1 \mathrm{~h}\left(\mathrm{~T}_{\max }\right)$. 
Following the intramuscular administration of tolfenamic acid as a single drug and in combination with moxifloxacin in the male and female rats, peak plasma drug concentration was significantly higher in the female rats compared to the male rats. It could be due to difference in the metabolic activity like glucoronidation (Pentikainen, 1984) in female which is supported by sex hormone dependency of phase II metabolism of NSAID drug in the rat (PalylykColwell and Jamali, 2004). Individual differences in metabolic response for both Phase I and Phase II enzymes are affected by external and internal factors including sex (Jancova et al. 2010). The plasma concentration-time profile of tolfenamic acid in the male and female rats of both treatment groups are illustrated in Figure 1 and Figure 2, respectively. Pharmacokinetic parameters of tolfenamic acid administered as single drug and co-administered with moxifloxacin in the male and female rats are summarized in Table 1.

Following the intramuscular administration of tolfenamic acid alone and in moxifloxacin-treated male wistar rats, the mean values of half-life $\left(\mathrm{T}_{1 / 2}\right)$, volume of distribution $\left(\mathrm{V}_{\mathrm{z}}\right)$, clearance $(\mathrm{Cl})$ and area under plasma drug concentration-time curve $\left(\mathrm{AUC}_{(0-\infty)}\right)$ of tolfenamic acid were $2.59 \pm 0.16$ and $3.27 \pm 0.32 \mathrm{hr}, 822.17 \pm 115.38$ and $1249.64 \pm$ $139.52 \mathrm{ml}, 218.39 \pm 25.47$ and $265.18 \pm 11.36$ $\mathrm{ml} / \mathrm{hr}$ and $20280.77 \pm 3501.67$ and $15229.18 \pm$ $678.80 \mathrm{hr} . \mathrm{ng} / \mathrm{ml}$, respectively. In the female rats, above mean values were $2.78 \pm 0.39$ and $2.66 \pm$ $0.53 \mathrm{hr}, 756.42 \pm 166.09$ and $559.68 \pm 76.19 \mathrm{ml}$, $179.76 \pm 20.01$ and $152.75 \pm 10.34 \mathrm{ml} / \mathrm{hr}$ and $23524.07 \pm 2324.79$ and $26830.41 \pm 1914.84$ $\mathrm{hr} . \mathrm{ng} / \mathrm{ml}$, respectively.

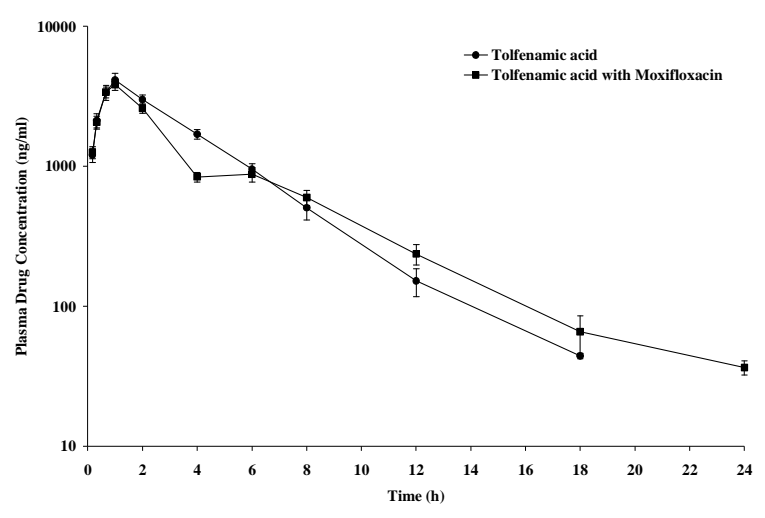

Figure 1 - Semi-logarithmic plot of plasma tolfenamic acid concentration following intramuscular administration of tolfenamic acid as single drug $(4 \mathrm{mg} / \mathrm{kg})$ and in combination with moxifloxacin $(5 \mathrm{mg} / \mathrm{kg})$ in male wistar rats $(\mathrm{n}=6)$. Each point represents Mean \pm SEM.

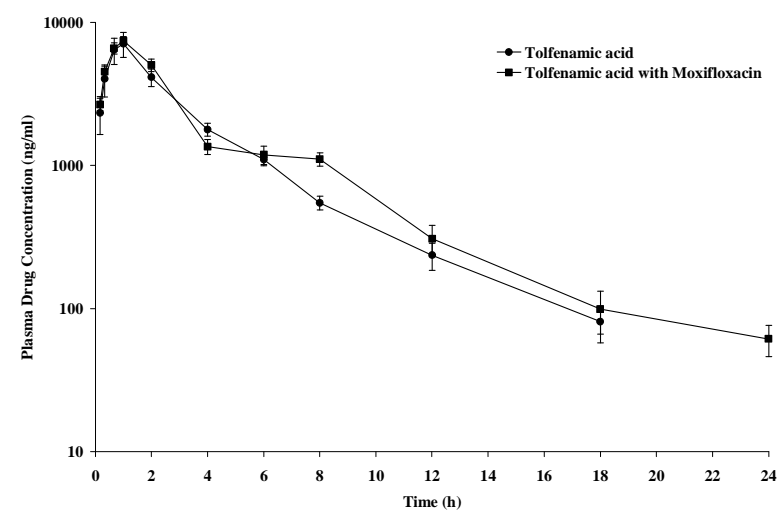

Figure 2 - Semi-logarithmic plot of plasma tolfenamic acid concentration following intramuscular administration of tolfenamic acid as single drug $(4 \mathrm{mg} / \mathrm{kg})$ and in combination with moxifloxacin $(5 \mathrm{mg} / \mathrm{kg})$ in female wistar rats $(\mathrm{n}=6)$. Each point represents Mean \pm SEM. 
Table 1 - Pharmacokinetic parameters of tolfenamic acid following its administration as single drug and in combination with moxifloxacin in male and female rats.

\begin{tabular}{cccccc}
\hline PK & \multirow{2}{*}{ Unit } & \multicolumn{2}{c}{ Tolfenamic acid alone } & \multicolumn{2}{c}{ Tolfenimic acid + Moxifloxacin } \\
\cline { 3 - 6 } parameters & & Male rats & Female rats & Male rats & Female rats \\
\hline $\mathrm{C}_{\max }$ & $\mathrm{ng} / \mathrm{ml}$ & $4111.44 \pm 493.15$ & $7114.74 \pm 1409.96^{*}$ & $3837.69 \pm 351.83$ & $7436.37 \pm 518.67 *$ \\
$\mathrm{~T}_{1 / 2}$ & $\mathrm{~h}$ & $2.59 \pm 0.16$ & $2.78 \pm 0.39$ & $3.27 \pm 0.32$ & $2.66 \pm 0.53$ \\
$\mathrm{~K}_{\mathrm{el}}$ & $\mathrm{h}^{-1}$ & $0.27 \pm 0.02$ & $0.27 \pm 0.04$ & $0.22 \pm 0.02$ & $0.30 \pm 0.04$ \\
$\mathrm{AUC}_{(0-\mathrm{t})}$ & $\mathrm{ng} . \mathrm{h} / \mathrm{ml}$ & $19954.89 \pm 3534.17$ & $23249.65 \pm 2330.59$ & $15032.74 \pm 698.81$ & $26559.23 \pm 1920.57$ \\
$\mathrm{AUC}_{(0-\infty)}$ & $\mathrm{ng} . \mathrm{h} / \mathrm{ml}$ & $20280.77 \pm 3501.67$ & $23524.07 \pm 2324.79$ & $15229.18 \pm 678.80$ & $26830.41 \pm 1914.84$ \\
$\mathrm{Vz}$ & $\mathrm{ml}$ & $822.17 \pm 115.38$ & $756.42 \pm 166.09$ & $1249.64 \pm 139.52^{*}$ & $559.68 \pm 76.19$ \\
$\mathrm{Cl}$ & $\mathrm{ml} / \mathrm{h}$ & $218.39 \pm 25.47$ & $179.76 \pm 20.01$ & $265.18 \pm 11.36$ & $152.75 \pm 10.34$ \\
\hline
\end{tabular}

* Significant at $\mathrm{p}<0.05$

$\mathrm{C}_{\max }$ : Maximum concentration; $\mathrm{T}_{1 / 2}$ : Elimination half-life; $\mathrm{K}_{\mathrm{el}}$ : Elimination rate constant; $\mathrm{AUC}_{(0-\mathrm{t})}$ : Area under the curve from zero to t time; $\mathrm{AUC}_{(0-\infty)}$ : Area under the curve from zero to infinity; Vz: Volume of distribution; Cl: Total body clearance.

Following the intramuscular administration of tolfenamic acid in moxifloxacin-treated male rats, the mean volume of distribution $(\mathrm{Vz})$ was significantly higher $(\mathrm{p}<0.05)$ compared to the volume of distribution found in the female rats as well as respective value in the rats given tolfenamic acid alone. Likewise, higher volume of distribution of tolfenamic acid was found in the morbofloxacin-treated calves (Sidhu et al. 2005). The volume of distribution in the male and female rats confirmed the extensive penetration of tolfenamic acid into various body fluids and tissues of the rats. McKellar et al. (1991) also reported a large volume of distribution for tolfenamic acid in the dogs, which could have been due to enterohepatic cycling. The enterohepatic re-cycling of tolfenamic acid has been reported in the men and camel (Pentikainen et al. 1984, Wasfi et al. 1998). Priymenko et al. (1993) showed that $90 \%$ of administered tolfenamic acid in the dog was excreted in bile, conjugated with glucuronic and sulphuric acids. Because of the change in plasma protein binding of most NSAIDs including TA in the presence of fluoroquinoles, alteration in distribution volume is usually observed (Pentikainen et al. 1981, Hardie et al. 1985, Lees et al. 1987). Intramuscular administration of moxifloxacin did not produce significant influence over the elimination processes of intramuscularly administered tolfenamic acid in the male and female rats. Likewise, enrofloxacin did not alter the pharmacokinetics of diclofenac sodium in the calves (Kumar et al. 2003). Pharmacokinetic and pharmacodynamic interaction of TA and marbofloxacin have also been reported in goats (Sidhu et al. 2010).
In establishing the relationships between the plasma concentration of the drug and its effect, it is necessary to keep in mind that the plasma concentrations do not reach instantaneously at the receptor level, thus there may be a further delay between the interaction with the receptor and the final response. The phenomenon of a delayed temporal response (hysteresis) has been reported for NSAIDs (Brugueras et al. 1978, Sacchetti et al. 1978, Graham 1987). Thus, PK/PD modeling is important to be considered for the inhibition of serum TxB2, exudate $\mathrm{PGE}_{2}$ and bradykinininduced swelling by tolfenamic acid. The mean $\mathrm{EC}_{50}$ value for serum $\mathrm{TxB} 2$ inhibition was reported to be $0.137 \pm 0.07 \mu \mathrm{g} / \mathrm{mL}$, with the corresponding values for the inhibition of $\mathrm{PGE}_{2}$ and bradykinin-induced swelling being $0.077 \pm$ $0.01,0.040 \pm 0.017$ and $0.030 \pm 0.02 \mu \mathrm{g} / \mathrm{mL}$, respectively in the calves (Landoni et al. 1996). Following the intramuscular administration of TA in normal and moxifloxacin-treated rats, the plasma drug concentration of $44.11 \pm 1.93$ and $36.36 \pm 4.18 \mathrm{ng} / \mathrm{mL}$ was observed at 18 and $24 \mathrm{~h}$, respectively in the present study.

The $\mathrm{C}_{\max }$ and volume of distribution of tolfenamic acid following the intramuscular administration were influenced by the gender difference or moxifloxacin administration in the rats; however, the AUC, elimination half-life and total body clearance tended to be similar between the groups that received a single dose of TA and TA along with moxifloxacin. In conclusion, the administration of moxifloxacin caused little alteration in the pharmacokinetics of tolfenamic acid in the male and female rats. It may not be uncommon to raise the awareness about the potential drug-drug interaction between tolfenamic acid and moxifloxacin. 


\section{ACKNOWLEDGMENTS}

We thank Mr. Pankaj R. Patel, CMD of Zydus Cadila Healthcare Ltd, Ahmedabad, India for providing the laboratory facility to carry out the research work. We are also thankful to Mr.Harilal Patel, Dr.Pradhyuman Gohil, Mr.Bharat Patel for technical support.

\section{REFERENCES}

Benet, L.Z. and Sheiner, L.B. (1985), Pharmacokinetics: The dynamics of drug absorption, distribution and elimination. In: Goodman and Gilman's, The Pharmacological Basis of Therapeutics. Macmillan, pp. 3-34.

Brugueras, N. E., Lezotte, L. A. and Moxley, T. E. (1978), Ibuprofen: a double blind comparison of a twice a day therapy with four times a day therapy. Clin. Therap. 2, 13-21.

Dalhoff, A., Petersen, U. and Endermann, R. (1996), Invitro activity of Bay-128039, a new 8methoxyquinolone. Chemother., 42, 410-425.

Graham, G. G. (1987), Pharmacokinetics and metabolism of non-steroidal anti-inflammatory drugs. Med. J. Austral., 147, 597-602.

Hardie, E.M., Hardee, G.E. and Rawlings, C.A. (1985), Pharmacokinetics of flunixin meglumine in dogs. Am. J. Vet. Res., 46, 235-237.

Hawkey, C. J. (1999), Cox-2 inhibitors. Lancet, 353, $307-$ 314.

Jancovaa, P., Anzenbacherb, P., Anzenbacherovaa, S.E. (2010), Phase II Drug Metabolizing Enzymes. Biomed. Pap. Med. Fac. Univ. Palacky. Olomouc. Czech. Repub., 154, 103-116.

Jaussaud, P., Guieu, D., Bellon, C., Barbier, B., Lhopital, R., Sechet, R., Courtout, D. and Toutain, P. L. (1991), Pharmacokinetics of Tolfenamic acid in the horse. Equine Vet. J., 16, 69-72.

Kankaanranta, H., Moilanen, E. and Vapaatalo, H. (1991), Tolfenamic acid inhibits iankotriene B4-induced chemotaxis of polymorphonuclear leukocytes in vitro. Inflam., 15, 137-143.

Kumar, N., Singh, S.D. and Jayachandra N.C. (2003), Pharmacokinetics of Enrofloxacin and Its Active Metabolite Ciprofloxacin and Its Interaction with Diclofenac after intravenous administration in buffalo calves. The Vet. J., 165, 302-306

Landoni, M.F., Cunningham, F.M. and Lees, P. (1996), Pharmacokinetics and pharmacodynamics of Tolfenamic acid in calves. Res.Vet. Sci., 61, 26-32.

Lees, P., Higgins, A. J., Sedgwick, A. D. and May, S. A. (1987), Applications of equine models of acute inflammation. Vet. Record., 120, 522-529.

Linden, I, Parantainen, J.and Vapaatalo, H. (1976), Inhibition of Prostaglandin Biosynthesis by Tolfenamic acid in Vitro. Scand. J. Rheumatol. 5, 129-132.
Lombardino, J.G. and Wiseman, E.H. (1982), Piroxicam and other. anti-inflammatory oxicams. Med. Res. Rev., 2, 127-152.

McKellar, Q. A, Galbraith, E. and Simmons, R. (1991), Pharmacokinetics and serum thromboxane inhibition of two NSAIDs when administered to dogs by the intravenous or subcutaneous route. J. Small Anim. Pract., 32, 335-340.

Miravitlles, M. (2007), Moxifloxacin in the management of exacerbations of chronic bronchitis and COPD. Int. $J$. Chron. Obstruct. Pulmon. Dis., 2, 191-204.

Palylyk-Colwell E.L., Jamali, F. (2004), Effect of gonadectomy and hormones on sex differences in ketoprofen enantiomer glucuronidation and renal excretion of formed glucuronides in the rat. Pharm. Res., 21, 989-95.

Pedersen, S.B. (1994), Biopharmaceutical aspects of tolfenamic acid. Pharmacol. Toxicol. 75 Suppl 2, 22-32.

Pentikainen, P. J, Neuvonen, P. and Backman, C. (1981), Human pharmacokinetics of Tolfenamic acid, a new anti-inflammatory agent. Europ. J. Clin. Pharmacol., 19, 359-365.

Pentikainen, P. J, Tokola, O, Alhava, E. and Penttilfi, A. (1984), Pharmacokinetics of Tolfenamic acid: Disposition in Bile, Blood and Urine After Intravenous Administration to Man. Eur. J. Clin. Pharmacol., 27, 349-354.

Priymenko, N., Ferre, J. P., Rascol, A., Costes, G. and Toutain, P. L. (1993), Migrating motor complex of the intestine and absorption of a biliary excreted drug in the dog. J. Pharmacol. Exp. Therap., 267, 1161-1167.

Proudman, K. E. and McMillan, R. M. (1991), Are Tolfenamic acid and tenidap dual inhibitors of 5lipoxygenase and cyclo-oxygenase? Agents Actions, 34, 121-124.

Rejholec, V., Vapaatalo, H., Tokola, O. and Gothoni, G. (1979), A comparative, double-blind study on Tolfenamic acid in the treatment of rheumatoid arthritis. Scandin. J. Rheumatol., 24, (Suppl), 13-16.

Sacchetti, G, Ferrati, G. C, Parrinello, L. and Salami, A. (1978), Kinetics of analgesic response in man; an example with two non-steroidal anti-inflammatory analgesic drugs. J. Inter. Med. Res., 6, 312-316.

Sidhu, P. K, Landoni, M. F. and Lees, P. (2005), Influence of marbofloxacin on the pharmacokinetics and pharmacodynamics of Tolfenamic acid in calves. J. Vet. Pharmacol. Therap., 28, 109-119.

Sidhu, P.K., Landoni, M.F., Lees, P. (2006), Pharmacokinetic and pharmacodynamic interactions of tolfenamic acid and marbofloxacin in goats. Res. Vet. Sci., 80, 79-90.

Wasfi, I.A, Elghazali, M, Hadi, A.A, Zorob, O, Boni, N.S, Alkatheeri, N.A. and Barezaiq I.M. (1998), Pharmacokinetics of Tolfenamic acid and its detection time in urine after intravenous administration of the drug in camels. Am. J. Vet. Res., 59, 1451-1458.

Received: June 07, 2010; Revised: December 28, 2010; Accepted: May 17, 2011 